\title{
Delayed allergic reaction to furosemide with a positive lymphocyte transformation test
}

\section{Reacción alérgica tardía a furosemida con positividad de la prueba de transformación de linfocitos}

\author{
Olga Patricia Monge-Ortega, ${ }^{1}$ Javier Domínguez-Ortega, ${ }^{2}$ Miguel González-Muñoz, ${ }^{3}$ Rosario Cabañas, ${ }^{2}$
} María Magdalena Lluch-Bernal, ${ }^{2}$ Ana Fiandor, ${ }^{2}$ Luz Yadira Bravo-Gallego, ${ }^{3}$ Santiago Quirce ${ }^{2}$

\begin{abstract}
Background: Furosemide is the most commonly prescribed loop diuretic worldwide. Although, its extended use, furosemide rarely induces allergic reactions. Until 2013, only 49 cases of furosemide allergy had been described.

Clinical case: We have reported on a patient who developed a delayed, erythematous and pruritic skin eruption after the ingestion of furosemide. The implication of furosemide in the reaction was established by a positive lymphocyte transformation test (LTT).

Conclusion: This is the first reported case of hypersensitivity to furosemide in which this drug was confirmed as the trigger by a positive LTT. LTT could become a decent diagnostic alternative for patients who experience delayed reactions to furosemide.
\end{abstract}

Keywords: Allergy; Delayed reaction; Furosemide; Lymphocyte transformation test

Este artículo debe citarse como: Monge-Ortega OP, Domínguez-Ortega J, González-Muñoz M, Cabañas R, Lluch-Bernal MM, Fiandor A, Bravo-Gallego LY, Quirce S. Reacción alérgica tardía a furosemida con positividad de la prueba de transformación de linfocitos. Rev Alerg Mex. 2019;66(2):254-256

ORCID

Olga Patricia Monge-Ortega, 0000-0002-6195-417X; Javier Domínguez-Ortega, 0000-0002-5397-2327;

Miguel González-Muñoz, 0000-0002-3957-4955; Rosario Cabañas, 0000-0001-8601-1728;

María Magdalena Lluch-Bernal, 0000-0002-5815-5211; Ana Fiandor, 0000-0003-0446-9562;

Luz Yadira Bravo-Gallego, 0000-0002-4919-5166; Santiago Quirce, 0000-0001-8086-0921

${ }^{1}$ Hospital San Juan de Dios, Departamento de Alergia, San José, Costa Rica

${ }^{2}$ Hospital La Paz, Departamento de Alergia, Madrid, España

${ }^{3}$ Hospital La Paz, Departamento de Inmunología, Madrid, España
Correspondencia: Olga Patricia Monge-Ortega. patmonor@hotmail.com

Recibido: 2018-03-11

Aceptado: 2018-07-09

DOI: 10.29262/ram.v66i2.371 


\section{Resumen}

Antecedentes: La furosemida es el diurético de asa más comúnmente prescrito en todo el mundo. A pesar de su amplio uso, rara vez induce reacciones alérgicas. Hasta 2013 solo se habían descrito 49 casos de alergia a la furosemida.

Caso clínico: Mujer de 68 años con hipertensión tratada con amlodipina, así como rinoconjuntivitis alérgica. Después del consumo de $40 \mathrm{mg}$ de furosemida por cinco días debido a edema bilateral maleolar presentó exantema cutáneo maculopapular, eritematoso y pruriginoso. Los resultados positivos en la prueba de transformación de linfocitos confirmaron la implicación de la furosemida en la reacción.

Conclusión: El caso que se reporta es el primero de hipersensibilidad a la furosemida en el que se confirma la implicación del fármaco por medio de una prueba de transformación de linfocitos positiva, la cual podría convertirse en una alternativa diagnóstica para los pacientes que experimentan reacciones adversas tardías a la furosemida.

Palabras clave: Alergia; Reacción adversa tardía; Furosemida; Prueba de transformación de linfocitos

\section{Antecedentes}

La furosemida es el diurético de asa más recetado en el mundo. ${ }^{1}$ A pesar de su uso prolongado, la furosemida rara vez induce reacciones alérgicas. Hasta 2013 solo se habían descrito 49 casos de alergia a la furosemida, con una edad media de 60.5 años. ${ }^{2}$ Las reacciones tipo 1 , como la anafilaxia, solo se informaron una vez por vía oral ${ }^{3} \mathrm{y}$ por administración intravenosa del fármaco; ${ }^{4}$ incluso se ha propuesto un protocolo de desensibilización oral rápida. ${ }^{5} \mathrm{~A}$ la inversa, se han notificado reacciones graves de hipersensibilidad, incluidos casos de síndrome de Stevens-Johnson ${ }^{6}$ y pustulosis exantemática generalizada aguda. ${ }^{7}$ Aunque la furosemida está incluida en las sulfonamidas no aromáticas, no ha sido claramente demostrado un mecanismo de reactividad cruzada entre este grupo y los antibióticos de sulfonamidas.

\section{Caso clínico}

Mujer española de 68 años, con antecedentes de hipertensión tratada con amlodipina y rinoconjuntivitis alérgica por Cupressus arizonica; no indicó otro antecedente significativo. En septiembre de 2016 fue atendida en el Servicio de Urgencias del Hospital Universitario La Paz de Madrid. Había tomado $40 \mathrm{mg}$ de furosemida diariamente durante cinco días debido a edema maleolar bilateral, con la que desarrolló una lesión maculopapular en la piel, eritematosa y levemente pruriginosa, que comenzó en el tercio distal de ambas extremidades inferiores y avanzó hacia el resto de las piernas, extremidades superiores y tronco. Presentó intensa picazón vaginal y anal sin lesiones cutáneas o mucosas. Cuando fue evaluada en la sala de urgencias, se le indicó suspender el medicamento y fue tratada con $20 \mathrm{mg}$ de bilastina y $1 \mathrm{mg} / \mathrm{g}$ de aceponato de metilprednisolona en crema, con lo que se observó mejoría clínica a los 10 días.

La paciente no había mostrado con anterioridad reacciones a los medicamentos, incluidas las sulfamidas o los cosméticos. Se llevaron a cabo pruebas cutáneas con bacterias y alimentos inhalantes; fueron positivas solo para los pólenes de pasto, de Olea europaea y Cupressus arizonica. Fueron negativas para el resto de los aeroalérgenos probados, alimentos, látex, Anisakis simplex, gliadina, una proteína de transporte de lípidos de melocotón estandarizada y furosemida $(10 \mathrm{mg} / \mathrm{mL}){ }^{8}$

Seis meses después del episodio se realizaron pruebas epicutáneas con True Test ${ }^{\circledR}$ estándar (Smart Practice, Dinamarca) y furosemida (1\% en vaselina), ${ }^{8}$ las cuales fueron negativas. En un intento por aclarar el mecanismo subyacente, se realizó una prueba de transformación de linfocitos con furosemida. La proliferación de linfocitos del paciente alérgico se midió como ha sido descrito: ${ }^{9,10}$ las células mononucleares de sangre periférica frescas 


\begin{tabular}{|c|c|c|c|c|}
\hline \multicolumn{5}{|c|}{$\begin{array}{l}\text { Cuadro 1. Índice de estimulación obtenido con diferentes concen- } \\
\text { traciones de furosemida }\end{array}$} \\
\hline & \multicolumn{4}{|c|}{ Furosemida $(\mu \mathrm{g} / \mathrm{mL})$} \\
\hline & 200 & 100 & 50 & 10 \\
\hline Paciente & 2.4 & 3.1 & 1.6 & 0.6 \\
\hline Control 1 & 0.7 & 1.2 & 0.8 & 1.0 \\
\hline Control 2 & 0.8 & 1.5 & 1.5 & 0.8 \\
\hline
\end{tabular}

fueron separadas sobre un gradiente de densidad (Histopaque-1077 ${ }^{\circledR}$, Sigma-Aldrich) y durante seis días se incubaron $10^{6}$ células $/ \mathrm{mL}$ por triplicado con furosemida $(200 \mu \mathrm{g} / \mathrm{mL}-10 \mu \mathrm{g} / \mathrm{mL})$. Se utilizó fi- tohemaglutinina $(5 \mu \mathrm{g} / \mathrm{mL})$ como control positivo. La proliferación se determinó mediante la adición de $\left[{ }^{3} \mathrm{H}\right]$ timidina $(0.5 \mu \mathrm{Ci} /$ pocillo $)$ durante las 18 horas finales del periodo de incubación. Las respuestas proliferativas se calcularon como índices de estimulación, definidos como la relación entre los valores medios de conteos por minuto en cultivos con antígeno y los obtenidos sin antígeno. Se obtuvo respuesta positiva con la furosemida, definida como un índice de estimulación $>2$. La prueba de transformación de linfocitos con furosemida para dos sujetos control diferentes no mostró respuestas proliferativas (cuadro 1). Como el paciente se negó a someterse a cualquier otra prueba in vivo, no se realizó prueba oral con el fármaco responsable.

\section{Referencias}

1. Wargo K, Banta WM. A comprehensive review of the loop diuretics: should furosemide be first line? Ann Pharmacother. 2009;43(11):1836-1847. DOI: 10.1345/aph.1M177

2. Hwang TJ, Darge K. Furosemide allergy in children: separating the facts from the myths. Pediatr Radiol. 2013;43(10):1409-1410. DOI: 10.1007/s00247-013-2761-7

3. Domínguez-Ortega J, Martínez-Alonso J, Domínguez-Ortega C, Fuentes MJ, Frades A, FernándezColino. Anaphylaxis to oral furosemide. Allergol Immunopathol (Madr). 2003;31(6):345-347. DOI: 10.1016/S0301-0546(03)79210-6

4. Hansbrough JR, Wedner HJ, Chaplin DD. Anaphylaxis to intravenous furosemide. J Allergy Clin Immunol. 1987;80(4):538-541. DOI: 10.1016/0091-6749(87)90004-2

5. Alim N, Patel JY. Rapid oral desensitization to furosemide. Ann Allergy Asthma Immunol. 2009;103(6):538. DOI: 10.1016/S1081-1206(10)60274-8

6. Wright AA, Vesta KS, Stark JE, Smith WJ. Stevens-Johnson syndrome associated with furosemide: a case report. J Pharm Pract. 2010;23(4):367-370. DOI: 10.1177/0897190010362260

7. Noce R, Paredes BE, Pichler WJ, Krähenbühl S. Acute generalized exanthematic pustulosis (AGEP) in a patient treated with furosemide. Am J Med Sci. 2000;320(5):331-333. DOI: 10.1097/00000441200011000-00006

8. Lobera-Labairu T, Padial M, Guerrero M. Concentraciones de principios activos y excipientes empleados para la realización de pruebas cutáneas. En: Dávila I, Jáuregui I, Olaguibel J, Zubeldia J, editores. Tratado de alergología. España: Ergón; 2016.

9. Ariza A, Montanez M, Fernández TD, Perkins JR, Mayorga C. Cellular tests for the evaluation of drug hypersensitivity. Curr Pharm Des. 2016;22:6773-6783. DOI: 10.2174/1381612822666161107165917

10. Monge-Ortega OP, Domínguez-Ortega J, González-Muñoz M, Cabañas R, Lluch-Bernal M, Fiandor A, et al. Delayed allergic reaction to amlodipine with a positive lymphocyte transformation test. Rev Alerg Mex. 2017;64(4):505-508. DOI: 10.29262/ram.v64i4.312 